\title{
The Effect of Terrain Roughness in the Microwave Line-of-Sight Multipath Fading Estimation Based on Rec. ITU-R P.530-15
}

\author{
Polat Göktaş*1, Ayhan Altıntaş ${ }^{1,2}$, Satılmis Topçu², and Ezhan Karaşan ${ }^{1}$ \\ ${ }^{1}$ Department of Electrical and Electronics Engineering, Bilkent University, Ankara 06800, Turkey \\ pgoktas@ee.bilkent.edu.tr, altintas@ee.bilkent.edu.tr and ezhan@ee.bilkent.edu.tr \\ 2 Bilkent University - ISYAM, Ankara 06800, Turkey \\ topcu@ee.bilkent.edu.tr
}

\begin{abstract}
Multipath fading is an important constraint on the prediction of path loss for terrestrial line-of-sight microwave links. The International Telecommunication Union - Radiocommunication (ITU-R) Rec. P.530 [1] is one of the most widely used methods providing guidelines for the design of terrestrial line-of-sight links. The purpose of the study presented in this paper is to make an investigation of the effect of both terrain roughness and geoclimatic factor parameters in the path loss characteristics of microwave line-of-sight (LOS) propagation in NATO Band 3+ (1350 $2690 \mathrm{MHz})$ and NATO Band $4(4440-5000 \mathrm{MHz})$ frequency ranges. The two parameters led to significantly different results for the link availability due to multipath fading as a function of the fade margin.
\end{abstract}

\section{Introduction}

The estimation of path loss and link availability is necessary for the design of line-of-sight radio-relay systems. A worldwide path loss prediction model has been recommended by the Radiocommmunication Sector of the International Telecommunication Union (ITU-R) in Recommendation ITU-R P.530 [1]. This recommendation is used to predict both path loss and link availability in the average worst month for microwave links. Rec. ITU-R P.530 [1] path loss prediction model is composed of four significant clear-air and rainfall propagation mechanisms on terrestrial line-ofsight links: fading or enhancement due to multipath effects, diffraction loss over terrain obstruction, attenuation due to hydrometeors and depolarization (XPD). This paper focuses on multipath propagation model in clear-air environment for terrestrial line-of-sight links.

In this paper, we first analyse the theoretical prediction method of flat fading (such as worst month outage probability) based on Rec. ITU-R P.530. Then, we define how to find out the standart deviation of terrain height and investigate the effect of terrain roughnesss on the worst month outage probability for an example link in Istanbul, Turkey.

\section{Mathematics of Multipath Fading Model}

Link unavailability due to multipath fading in the average worst month depends on the effects of climate and terrain data. $S_{a}[1]$ is defined as the standard deviation of terrain heights $(\mathrm{m})$ within a $110 \mathrm{~km} \times 110 \mathrm{~km}$ area in Rec. ITU-R P.530. The worldwide data for this parameter is provided by ITU-R Study Group 3.

Another parameter needed to calculate the link availability of terrestrial line-of-sight links is the geoclimatic factor. There are two ways to calculate this parameter: a quick calculation (QC) method and a detailed link design (DLD) method.

- The quick calculation (QC) method uses only, $d N_{1}[1,2]$, point refractivity gradient in the lowest $65 \mathrm{~m}$ of the atmosphere not exceeded for $1 \%$ of an average year as shown in Equation (1). The worst month outage probability, $p_{w}$, is calculated by using Equations (2) and (3) in the quick calculation (QC) method.

ITU-R P.530-15 [1] Quick Calculation Method

$$
\begin{aligned}
& \mathrm{K}=10^{-4.6-0.0027 d N_{1}} \\
& p_{o}=K d^{3.1}\left(1+\left|\varepsilon_{p}\right|\right)^{-1.29} f^{0.8} \times 10^{-0.00089 h_{L}} \\
& p_{w}=p_{o} \times 10^{\frac{-A}{10}}
\end{aligned}
$$


- The detailed link design (DLD) method uses both $d N_{1}$ and $S_{a}$ parameters as shown in Equation (4). The percentage of time that fade depth A (in decibels) is exceeded in the average worst month is calculated by using Equations (5) and (6).

ITU-R P.530-15 [1] Detailed Link Design Method

$$
\begin{aligned}
& \mathrm{K}=10^{-4.4-0.0027 d N_{1}}\left(10+S_{a}\right)^{-0.46} \\
& p_{o}=K d^{3.4}\left(1+\left|\varepsilon_{p}\right|\right)^{-1.03} f^{0.8} \times 10^{-0.00076 h_{L}} \\
& p_{w}=p_{o} \times 10^{\frac{-A}{10}}
\end{aligned}
$$

The parameters $d N_{1}, S_{a},\left|\varepsilon_{p}\right|$ and $h_{L}$ significantly affect the fade occurrence factor, $p_{o}$ and unavailability due to multipath fading probability, $p_{w}$. Equations (3) and (6) are used for a deep-fading prediction method (for small percentage of time) but for all percentage of time $A$ must be replaced by $A_{t}$, the fade depth at which the transition occurs between deep-fading and shallow-fading distribution.

\section{Impact of Terrain Roughness Parameter in Multipath Fading Estimation}

We calculate the standard deviation of terrain heights, $S_{a}$ which is a parameter in the performance prediction of the microwave radio links. The method calculates the mean of the terrain heights in a specified window around the point of interest as shown in Equation (7).

$$
\bar{x}=\frac{\sum_{i=1}^{n} x_{i}}{n}
$$

Then, the standard deviation of the terrain heights $(\sigma)$ is calculated according to the following equation

$$
\sigma=\sqrt{\sum_{i=1}^{n} \frac{\left(x_{i}-\bar{x}\right)^{2}}{n-1}}
$$

where $n=$ number of path profile points

$x_{i}=$ height (above sea level) of the i-th profile point

The worldwide $S_{a}$ data provided by ITU-R is too coarse such that the distance between grid points is $110 \mathrm{~km}$. If the path distance between transmitter and receiver sites is less than $110 \mathrm{~km}, S_{a}$ parameter is computed by using bi-linear interpolation of four gridpoints. We change the resolution of terrain roughness data and investigate its effect on the link availability. The path profile between transmitter and receiver sites is constructed by using a Digital Map in DTED format that has a resolution of $3 \times 3$ seconds (approximately 100 meters). Terrain roughness data is provided with the different moving window sizes. Different resolutions of $S_{a}$ and the number of terrain points used in the calculation of $S_{a}$ are given in Table 1.

Table 1. Different resolutions of $S_{a}$ and number of terrain points in $S_{a}$ data file

\begin{tabular}{|c|c|}
\hline Resolution & Number of terrain gridpoints \\
\hline 30 seconds & $121 \times 121$ \\
\hline 1 minutes & $61 \times 61$ \\
\hline 5 minutes & $13 \times 13$ \\
\hline 10 minutes & $7 \times 7$ \\
\hline
\end{tabular}

To confirm this observation on the link availability, we applied simulation on terrestrial line-of-sight link located in Istanbul, Turkey. Figure 1 shows base station sites for microwave links studied in Istanbul. The path length of the Çataltepe - Beylikdüzü radio link is $55.448 \mathrm{~km}$. The main parameters of this link are summarized in Table 2. As illustrated in Figure 2, clearance of the first Fresnel zone is investigated in the microwave link analysis. The path profile of the link is used in the analysis considering the curvature of the Earth. 
Table 2. Terrestrial link parameters for Çataltepe - Beylikdüzü microwave LOS link

\begin{tabular}{|c|c|}
\hline Parameter & Description \\
\hline Transmitter Station & Çataltepe $41^{\circ}{\mathrm{N} 02^{\prime}}^{\prime} 58.00^{\prime \prime} 29^{\circ} \mathrm{E} 17^{\prime} 48.00^{\prime \prime}$ \\
\hline Receiver Station & Beylikdüzü $41^{\circ}{\mathrm{N} 01^{\prime}}^{\prime} 06.00^{\prime \prime} 28^{\circ} \mathrm{E} 38^{\prime} 17.00^{\prime \prime}$ \\
\hline $\begin{array}{l}\text { Altitude of transmitter station } \\
\text { (a.s.l) }\end{array}$ & $300 \mathrm{~m}$ \\
\hline $\begin{array}{c}\text { Altitude of receiver station } \\
\text { (a.s.l) }\end{array}$ & $150 \mathrm{~m}$ \\
\hline $\begin{array}{l}\text { Height of receiving antenna } \\
\text { (a.g.l) }\end{array}$ & $20 \mathrm{~m}$ \\
\hline Radio Frequency & $2 \mathrm{GHz}$ \\
\hline Path Length & $55.448 \mathrm{~km}$ \\
\hline Path Inclination & $2.69 \mathrm{mrad}$ \\
\hline$d N_{1}$ & $-451.5 \mathrm{~N}$-units $/ \mathrm{km}$ \\
\hline Free Space Loss & $133.4 \mathrm{~dB}$ \\
\hline
\end{tabular}

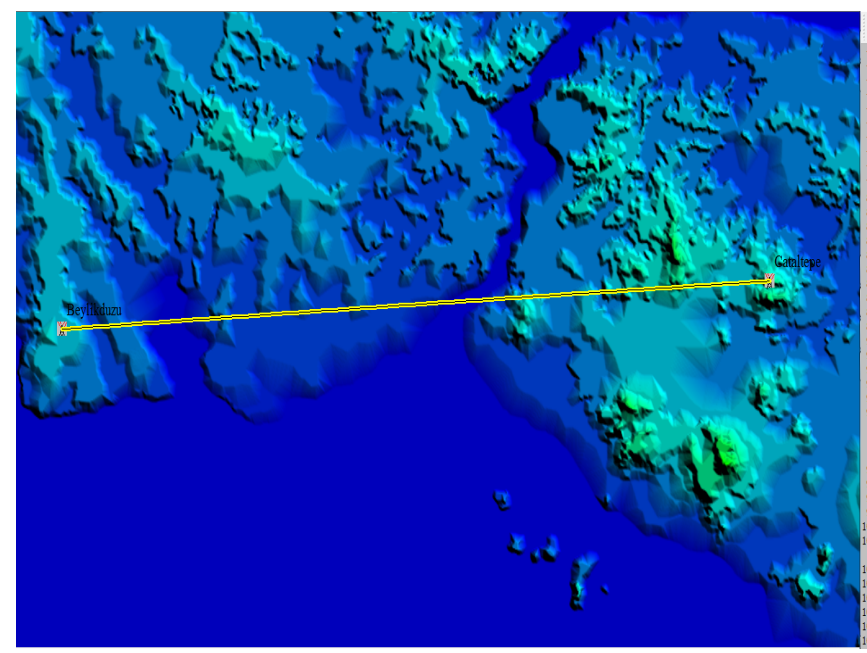

Figure 1. Location of sites used for microwave link simulation in Istanbul, Turkey

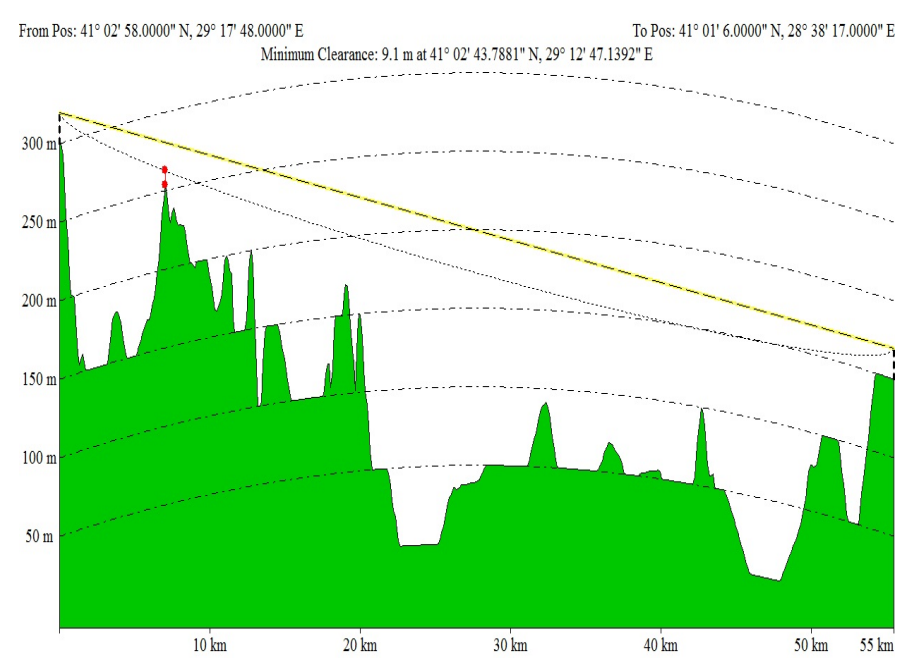

Figure 2. Cataltepe - Beylikdüzü Radio Link LOS Analysis, first Fresnel zone is indicated by the curve under the LOS path

In this paper, there are two different ways to calculate terrain roughness parameter: mean and midpoint path profile point. In the first case, the associated latitude and longitude of each profile point is determined along the Çataltepe Beylikdüzü path using a fixed distance increment. Terrain roughness data is found at each profile point in this radio link. Another investigation parameter is the impact of the midpoint terrain roughness on the link availability in example radiolink. The coordinates of the midpoint is obtained from the average of transmitter and receiver site coordinates. If the location coordinates along the path are different from the gridpoints, the standard deviation of terrain heights at the desired location is computed by performing a bi-linear interpolation on the values at the four closest gridpoints. The results are summarized in Table 3. The comparison of the results are presented on Figure 3(a) to Figure 3(b) in terms of predicted worst month unavailability.

Table 3. Terrain roughness data $\left(S_{a}\right)$ for different window size in Çataltepe - Beylikdüzü microwave LOS link

\begin{tabular}{|c|c|c|c|c|c|c|c|c|c|}
\hline $\begin{array}{c}30 \\
\text { second moving } \\
\text { window size }\end{array}$ & \multicolumn{2}{|c|}{$\begin{array}{c}\text { minutes moving } \\
\text { window size }\end{array}$} & \multicolumn{2}{|c|}{$\begin{array}{c}\text { 5 minutes moving } \\
\text { window size }\end{array}$} & $\begin{array}{c}\text { 10 minutes moving } \\
\text { window size }\end{array}$ & \multicolumn{2}{c|}{$S_{a}$ given by ITU } \\
\hline Mean & Midpoint & Mean & Midpoint & Mean & Midpoint & Mean & Midpoint & Mean & Midpoint \\
\hline 10.7 & 6.1 & 16.7 & 10.3 & 36.3 & 21.1 & 47.5 & 38.7 & 134.4 & 128.0 \\
\hline
\end{tabular}




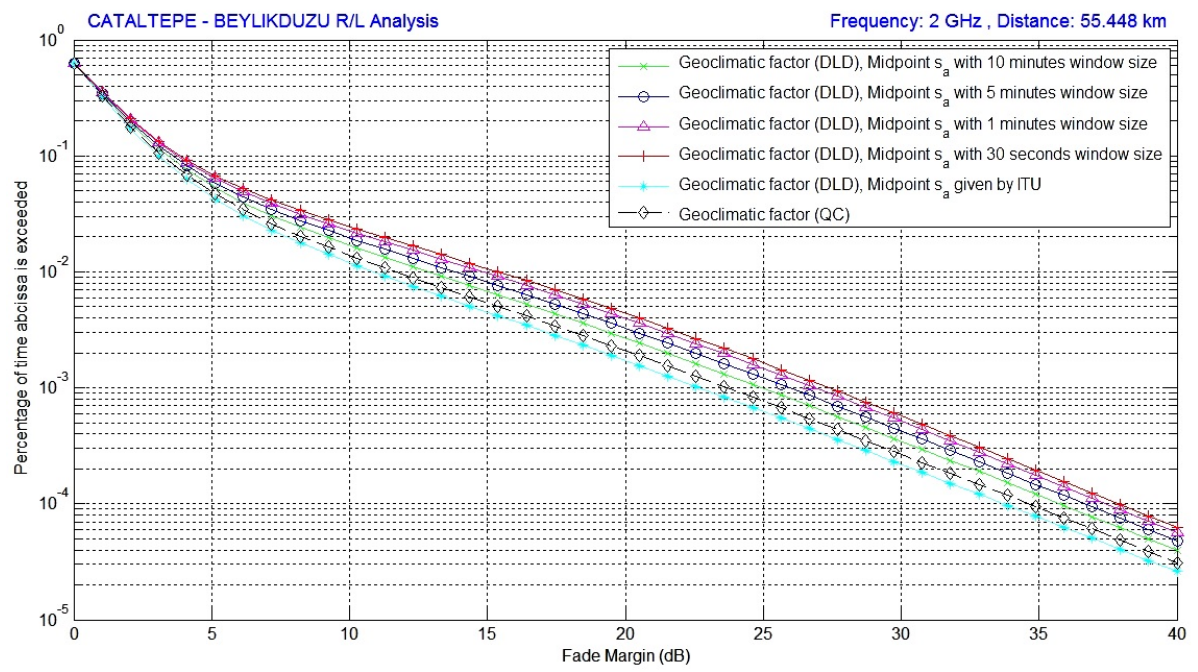

(a) Predicted worst month unavailability as function of midpoint terrain roughness value

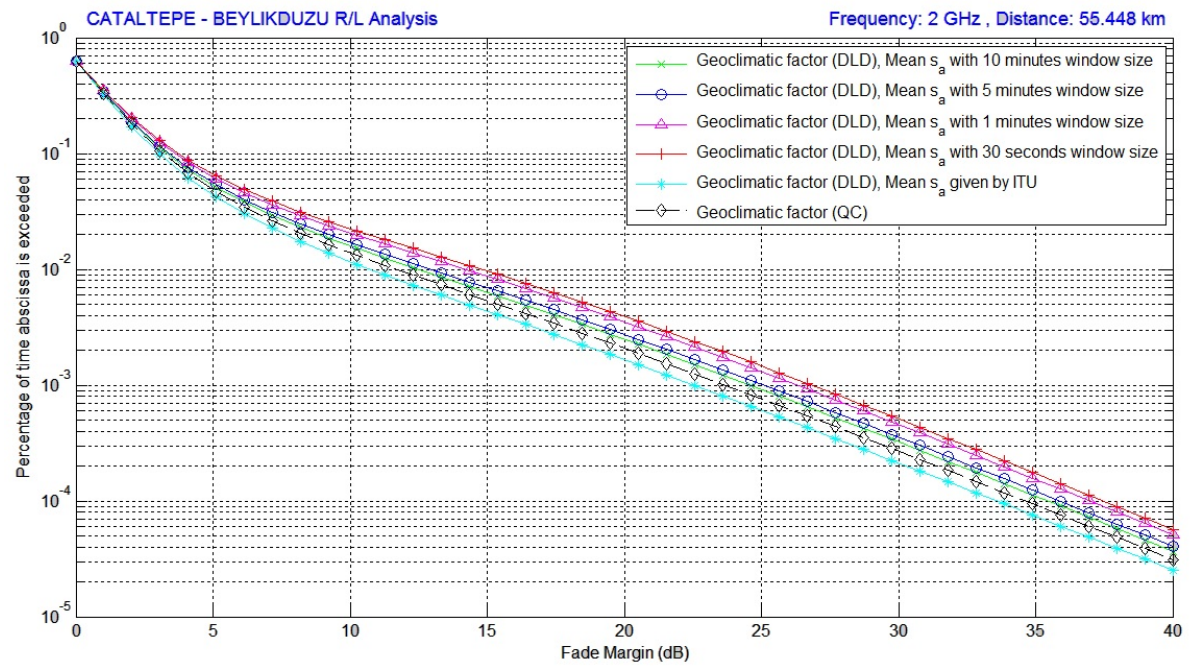

(b) Predicted worst month unavailability as function of mean terrain roughness value

Figure 3. Percentage of time $\left(p_{w}\right)$ that fade depth $(A)$ is exceeded in an average worst month

\section{Conclusion}

The multipath fading outage prediction method proposed by Recommendation ITU-R P.530 [1] is studied. We compared two methods of terrain roughness calculation on terrestrial microwave line-of-sight links. The effect of geoclimatic factor and different resolutions of terrain roughness data is investigated on the worst month link unavailability in Çataltepe - Beylikdüzü microwave radio link. At the fixed unavailability $\left(p_{w}=10^{-3}\right)$, fade margin can change up to $5 \mathrm{~dB}$ as shown in Figure 3. It can be seen that multipath fading prediction model with the terrain roughness data provided by ITU is optimistic. The future work will be focused on field measurements which will be used for better comparison of simulation results.

\section{References}

1. International Telecommunication Union, "Propagation data and prediction methods required for the design of terrestrial line-of-sight systems," Recommendation ITU-R P. 530-15, 2013.

2. International Telecommunication Union, "The radio refractive index: its formula and refractivity data," Recommendation ITU-R P. 453-10, 2012. 